\title{
La re-significación nietzscheana de virtud desde el horizonte de una autonomía post metafísica
}

Lucas Diel

UNNE

I diel@hotmail.com

Recibido 15/06/2017

Aprobado 22/09/2017

\section{Resumen}

A partir de un sintético recorrido por la crítica de Nietzsche al concepto moderno de autonomía, es decir, aquella concepción que asevera la existencia de un Yo puro y libre de condicionantes biológicos o históricos; pretendemos desentrañar cuál es el sentido nuevo que adquiere en el pensamiento nietzscheano el concepto de libertad. Esta reconstrucción posibilitará adentrarse en la afirmación de una ética nietzscheana que ya no aborde a los individuos separados de sus impulsos más primitivos o de su herencia. Sino que, más bien, considere la transformación de los instintos reactivos en fuerzas activas, en creaciones de estilos de vida o modos de conducirse que tengan vinculación directa con la vida.

Palabras clave: Nietzsche, ética, libertad, Kant

\section{Abrtract}

From a synthetic journey through Nietzsche's criticism to the modern concept of autonomy, that is, that conception that asserts the existence of a pure I and free of biological or historical conditioning factors; We intend to unravel what is the new meaning that the concept of freedom acquires in Nietzschean thought. This reconstruction will make it possible to enter into the affirmation of a Nietzschean ethic that no longer addresses individuals separated from their most primitive impulses or their inheritance. Rather, consider the transformation of reactive instincts into active 
forces, into lifestyle creations or modes of conduct that have a direct connection with life.

Keywords: Nietzsche, ethics, freedom, Kant

\section{Introducción}

El afán por desentrañar una ética vitalista en el pensador alemán viene dado por aportar a la resolución del problema que guía el presente escrito: ¿Dónde se abre la brecha para la soberanía de sí, allí donde se afirma que las acciones del hombre son necesarias (lo cual significa que responden a las resoluciones de una voluntad de poder interpretante del mundo)? En otras palabras, si la voluntad de poder es necesaria, ¿dónde cabe el espacio para la libertad? Solo desde una visión post metafísica, es decir, que elimine los dualismos contrapuestos, puede pensarse un tipo de libertad incluso dentro de la necesidad.

\section{Libertad y autonomía en la etapa moderna}

Si bien es cierto que Nietzsche defiende una particular idea de autonomía sobre todo al final de su obra, se trata de una autonomía alejada del modo moderno de concebirla $^{1}$, pues incorpora a esta los conceptos de diferencia y jerarquía en las acciones, que le darán un matiz más complejo a la idea; además de apartarse de la concepción moderna de sujeto consciente, ingresando a un campo nuevo para la filosofía: el cuerpo como interpretador, valorador, creador. Algo similar sucede con la idea de libertad, pues se rechaza en la obra de Nietzsche la orientación igualitarista de la libertad y se inicia una disquisición genealógica sobre las concepciones filosóficas

\footnotetext{
${ }^{1}$ Puede señalarse como una tesis básica de las líneas dominantes dentro de la filosofía moderna, por un lado, la postulación de la reflexividad de la conciencia como aquello que fundamenta toda predicación legítima sobre la realidad y que, de esta forma, asegura la posibilidad de un conocimiento como representación fiel de los hechos. Por otro lado, debido a que dicha posición minimiza la importancia e injerencia de factores concretos o contextuales (sea la historia, las costumbres, la corporalidad, etc.), se afirma el carácter soberano de la conciencia, lo cual queda de manifiesto en el predomino del pensamiento $-\mathrm{o}$ del $\mathrm{Yo}-$ sobre los diferentes tipos de acciones que pueden llevar a cabo los individuos, haciendo especial énfasis en la relación de conocimiento.
} 
clásicas de entender esta idea. Por otro lado, cabe destacar un segundo sentido del término "libertad" y que será objeto de controversia hacia el interior del pensamiento nietzscheano: se trata de la libertad en el sentido de autonomía, el hecho de que el individuo pueda ser su autolegislador sin depender de las leyes de su comunidad ni siendo funcional a esta. Todo el análisis de Nietzsche sobre los librepensadores modernos en su etapa ilustrada denota la presencia de este ideal de libertad. Pero Nietzsche se ocupará de llevar el problema hacia un lugar más elemental aún: el hecho de que ningún individuo está exento de responder al mando o a la obediencia.

Ser la causa de sí mismo, el único responsable de la propia existencia y de la propia acción: esa es la concepción que Nietzsche presenta como una ficción en el parágrafo 21 de Más allá del bien y del mal y que tratará de desarticular en gran parte de sus escritos por tratarse de uno de los engaños más perjudiciales sostenido a lo largo de la modernidad. Justamente en este aforismo el autor afirma que no se debería hablar de una voluntad libre o no-libre, sino de una voluntad fuerte y una débil ${ }^{2}$.

Si bien es cierto que Nietzsche no discute directamente con Kant, puede conjeturarse, a partir de las lecturas que hizo el filósofo alemán de los neokantianos de su época (Küno Fischer, Otto Liebmann y Afrikan Spir) ${ }^{3}$, que en el trasfondo de su crítica está presente la idea kantiana de autonomía, pues representa la antítesis de su

\footnotetext{
2 "No debemos cosificar equivocadamente «causa» y «efecto», como hacen los investigadores de la naturaleza (y quien, como ellos, naturaliza hoy en el pensar -) en conformidad con el dominante cretinismo mecanicista, el cual deja que la causa presione y empuje hasta que «produce el efecto»; debemos servirnos precisamente de la «causa», del «efecto» nada más que como de conceptos puros, es decir, ficciones convencionales, con fines de designación, de entendimiento, pero no de explicación. En lo «en-sí» no hay «lazos causales», ni «necesidad», ni «no-libertad psicológica», allí no sigue «el efecto a la causa», allí no gobierna «ley» ninguna. Nosotros somos los únicos que hemos inventado las causas, la sucesión, la reciprocidad, la relatividad, la coacción, el número, la ley, la libertad, el motivo, la finalidad; y siempre que a este mundo de signos lo introducimos ficticiamente y lo entremezclamos, como si fuera un «en sí», en las cosas, continuamos actuando de igual manera que hemos actuado siempre, a saber, de manera mitológica. La «voluntad no libre» es mitología: en la vida real no hay más que voluntad fuerte y voluntad débil”. NIETZSCHE, F. Más allá del bien y del mal. Trad. Andrés Sánchez Pascual, Alianza, Bs. As., 1984, p. 45.

${ }^{3}$ En un artículo de Elena Calvo, pueden rastrearse estos intermediarios de la lectura que hizo Nietzsche del filósofo de Könisberg, así como también la importancia que le dio Nietzsche a Kant en lo referido a sus críticas a la metafísica y la ética. Ver: CALVO, E. La crítica de la Moral Kantiana desde Nietzsche. En: Revista Espiga, Año X, Julio-Diciembre de 2011, pp. 1-9. También resulta de sumo interés el estudio de SÁNCHEZ, S. Lógica, verdad y creencia: algunas consideraciones sobre la relación Nietzsche-Spir. Universitas, Córdoba, 2001.
} 
pensamiento. ${ }^{4}$ Esta contraposición teórica adquiere relevancia al tomar en cuenta la crítica de Nietzsche a la idea del deber pretendido universal que se propone desde la filosofía kantiana. La crítica de Nietzsche al pensamiento moral kantiano viene desde varios frentes, pero específicamente se hace referencia al universalismo moral planteado por el pensador de Könisberg, al pretender establecer una idea del deber ser que sobrevuele la cabeza de todos los hombres:

$$
\begin{aligned}
& \text { "(...) más de un moralista quisiera ejercer sobre la humanidad su poder y su } \\
& \text { capricho de creador; otros, acaso precisamente también Kant, dan a } \\
& \text { entender con su moral: <lo que en mí es respetable es el hecho de que yo } \\
& \text { puedo obedecer, - iy en vosotros las cosas no deben ser distintas que en } \\
& \text { mí>-“. }
\end{aligned}
$$

Resulta interesante resaltar estas diferencias de perspectiva sobre el tema de la autonomía, porque muestran el quiebre con una tradición ética que se fundamenta en la libertad de la voluntad, una idea de la que Nietzsche se ocupó de resignificar a lo largo de sus escritos del período ilustrado. ${ }^{6}$ Cuando el sujeto se autopercibe en oposición a una naturaleza que le afecta y además cree que no está sujeta al devenir de esa naturaleza, escapando de sus leyes, está puesta en juego una idea metafísica de la voluntad y también una visión teleológica donde opera una razón superior que guía las conductas. $^{7}$

Kant fue un pensador representativo para esta postura. La noción de autonomía es una de las piezas maestras de la moral kantiana, pues constituye la base sobre la que se sedimentarán los principios de la razón práctica. ${ }^{8}$ La libertad puede

\footnotetext{
${ }^{4}$ Un escrito relevante que muestra desde qué ópticas Nietzsche vio en Kant un rival teórico es del Olivier Reboul. Nietzsche, crítico de Kant. Trad. Julio Quesada y José Lasaga, Anthropos, Barcelona 1993, donde el autor afirma que "Kant es el filósofo de quien Nietzsche más se ha ocupado. Desde luego, después de Schopenhauer y con mucho menos pathos. Pero con una seriedad que demuestra que había encontrado en el autor de las tres Críticas un contrincante de talla, un pensador frente al cual, contra el cual, le era necesario definirse y redefinirse sin descanso..., p. 3.

${ }^{5}$ NIETZSCHE, F. Más allá del bien y del mal. Trad. Andrés Sánchez Pascual. Madrid, Alianza, 1984, pp. 115-116.

${ }^{6}$ Puede destacarse el $\S 571$ de Humano, demasiado humano I o el $\$ 347$ de La ciencia jovial.

${ }^{7}$ Un lugar en la obra de Nietzsche donde se grafica una crítica a esa idea el aforismo $\$ 11$ de El Anticristo.

${ }^{8}$ No es novedoso el parangón del pensamiento de Nietzsche con el de Kant, hay una serie innumerable de artículos referidos al tema en general. Pero los menos de ellos refieren a la contraposición en lo referente a sus tipos de ética. Una afirmación cercana al supuesto en el que quiero sostener mi hipótesis, es
} 
darse en el hombre porque este no es enteramente una realidad natural (y aquí radicaría la diferencia esencial con el pensamiento de Nietzsche). Kant distingue tajantemente entre la naturaleza y la libertad trascendental; es lo que él Ilama "el tercer conflicto de las ideas trascendentales": una postura según la cual no solo las leyes naturales son las que dinamizan al mundo, sino que también los fenómenos pueden explicarse mediante una causalidad por libertad; y una antítesis, que sostiene la no existencia de libertad, es decir, la reducción de todo lo que acontece a leyes naturales ${ }^{9}$. La tensión entre naturaleza (necesidad) y libertad es relevante en tanto que son los únicos tipos de causalidad que se pueden concebir. Kant considera que en el mundo sensible solo puede admitirse una causalidad natural, pero también hay parte de libertad en el mundo, es decir, hay un carácter inteligible de la causalidad, pero que no lo podemos concebir porque se manifiesta en el orden nouménico de la realidad. Así, libertad y naturaleza coexisten.

Kant aplica su tesis al hombre y muestra que, respecto al carácter empírico, no puede hablarse de libertad, pues las acciones de orden fenoménico podrían predecirse si se tienen en cuenta sus condiciones previas. Sin embargo, si esas mismas acciones aisladas se conciben desde la razón práctica como causa que las produce, la libertad de la voluntad adquiere un papel fundamental, ya que no está sometida a las leyes espacio-temporales, por lo tanto le da un estatus de pura espontaneidad: "Si yo ahora (por ejemplo) me levanto con absoluta libertad de mi silla, y sin la influencia de las causas naturales (...), empieza absolutamente una nueva serie, aun cuando según el tiempo este suceso no sea más que la continuación de una serie precedente, pues esta decisión y este acto no se hallan en la secuencia de meros efectos naturales ni son su mera continuación" ${ }^{10}$. Aquí se propone una división parcial entre la dynamis física y el accionar de la voluntad, que se ubica en un plano diferente en el momento del acto, para romper la cadena de causalidades naturales.

expresado de forma sencilla por la Profesora Rosa Coll: "La contradicción a los instintos es contradicción a la vida y por ende síntoma de fatiga y de cansancio vital. Pero, la distancia entre ambas éticas se acorta a través de la noción -esencia para las dos- de voluntad, y de aquello que condiciona su obrar: la libertad. En Kant el menos nouménico de los noúmenos y el factum de su ética". COLL, R. Nietzsche: el pensador del sentido. En: "Immanuel Kant en el bicentenario de la publicación de la Crítica de la Razón Pura", Instituto Goethe de Córdoba, 1982, p. 22.

${ }^{9}$ Cfr. KANT. Crítica de la razón pura II. Trad. José Rovira Armengol. Losada, Bs. As., 1984, p. 332.

${ }^{10}$ Cfr. Ibíd., p. 335. 
En cierta medida, el sujeto trascendental kantiano puede establecerse leyes conductuales que se desprendan de las leyes físicas sometidas a las intuiciones espacio-temporales. Lo que Kant argumenta es que debe representarse un mundo en el cual la libertad sea posible más allá de la fatalidad del mundo de la necesidad. Este es el caso de lo que Kant llama buena voluntad, buena en sí misma, más allá de los fines: "En cuanto la buena voluntad saliera de sí para apoyarse en otra cosa o para demostrar hacia fuera lo genuino de su bondad, caería irremisiblemente en lo espacial, lo temporal, lo causalmente interconectado" ${ }^{11}$. Kant se refiere a un querer incondicionado que aspire a lo universal, para concretar esta aspiración hay un solo camino: ser legislador. Únicamente mediante la imposición de leyes el sujeto puede separarse del mecanismo de la naturaleza y realizar acciones autónomas; pero es necesario entender que estas leyes deben ser o transformarse en máximas universales. En ese sentido, las leyes a las que hay que obedecer son las leyes morales: "la moralidad es la condición bajo la cual un ser racional puede ser fin en sí mismo; porque solo por ella es posible ser miembro legislador en el reino de los fines” ${ }^{12}$. La suposición de un mundo moral hace que se deba pensar en una razón suprema que guíe las conductas individuales mediante normas morales y que, a su vez, sea causa de la naturaleza, pero siempre atendiendo a que la razón práctica tenga primacía sobre la teórica ${ }^{13}$.

Entonces, en lo referido al concepto de autonomía, no puede negarse que Kant ha sido el principal referente en la historia del pensamiento occidental, por supuesto que este ideal de autonomía dista muchísimo del de Nietzsche, quien le dará una impronta totalmente nueva y antitética a la autonomía kantiana.

Sin embargo, en lo que sí puede encontrarse un punto de conexión, es en que ambos autores entienden que la autodeterminación y la autolegislación deben

\footnotetext{
${ }^{11}$ ARANA, J. Los filósofos y la libertad. Síntesis, Madrid, 2005, p. 107.

${ }^{12}$ KANT, I. Fundamentación de la metafísica de las costumbres. Trad. M. García Morente, Espasa Calpe, Madrid, p. 93.

13 "La ley moral es, pues, un imperativo categórico que se impone como algo absoluto. El fundamento de tal imperativo es el deber. A este propósito, aclara Kant que no basta con que una acción sea conforme al deber para que tenga verdadero valor moral, es decir, para que sea calificada como buena; es preciso que quien actúe lo haga únicamente por deber, y no en virtud de inclinación alguna, pues toda inclinación es para Kant sensible". SANZ SANTACRUZ, V. De Descartes a Kant. Historia de la filosofía moderna. EUNSA, España, 2005, p. 450.
} 
provenir desde dentro. Solo que para Kant será la conciencia de la ley moral impresa en el hombre la que se sobrepondrá a la necesidad de la naturaleza y buscará imponerse como máxima universal para todos los hombres (imperativo categórico), en tanto que para Nietzsche será la voluntad de poder como instinto de libertad aquello que abrirá paso a la posibilidad de una autonomía que supere la eticidad de las costumbres y perseguirá la afirmación de la singularidad del individuo, alejándose de esta manera del formalismo kantiano.

\section{Voluntad de poder como instinto de libertad}

Sin caer en un mecanicismo, Nietzsche entiende -a partir de la lectura de la obra Lucha de las partes en el organismo. Una contribución al perfeccionamiento de la doctrina del finalismo mecanicista de Wilhelm Roux- que existe un tipo de libertad biológica que se entiende como despliegue de poder; también podría decirse, como expresión neta de una voluntad de poder. En este sentido, la libertad no es una facultad originaria en el hombre, pero se la consigue desarrollando ciertos aspectos propios de su faceta orgánica ${ }^{14}$. Esto supone un organismo que no solo puede adaptarse a su entorno sino que también impone cambios en él; frente a la teoría de la adaptación de Spencer (que fundamentaba la evolución de los organismos biológicos mediante su adaptación al medioambiente) Nietzsche afirma lo siguiente:

“(...) con ello se pasa por alto la supremacía de principio que poseen las fuerzas espontáneas, agresivas, invasoras, creadoras de nuevas interpretaciones, de nuevas direcciones y formas, por influjo de las cuales viene luego la <<adaptación〉>; con ello se niega en el organismo mismo el papel dominador de los supremos funcionarios, en los que la voluntad de vida aparece activa y conformadora"15.

\footnotetext{
${ }^{14}$ MÜLLER-LAUTER, Wolfgang, "Der Organismus als innerer Kampf. Der Einfluss von Wilhelm Roux auf Friedrich Nietzsche", Nietzsche-Studien, VII, 1978, p. 192: "Desde este periodo en adelante - se refiere Müller-Lauter en torno al año 1881- Nietzsche emplea en la descripción de los procesos orgánicos conceptos específicos de Roux, a veces con ligeras variaciones. En efecto, él habla de «autorregulación», de «recambio sobreabundante» y de «estímulo vital»".

${ }^{15}$ NIETZSCHE, F. La genealogía de la moral, Trad. Andrés Sánchez Pascual, Alianza, Bs. As., 2008, p. 102. No puede negarse la cercanía que Nietzsche tuvo con Spinoza respecto a este tema, quien fue un
} 
En este sentido, cabe rescatar un modo de entender la libertad en Nietzsche que podría considerarse biológico, y que se manifiesta cuando el individuo es capaz de desarrollar algunas cualidades orgánicas -idea que ha sido influenciada por el anatomista Wilhelm Roux- ${ }^{16}$.

Nietzsche abogará por apelar a un instinto de libertad existente en todos los hombres que denominará voluntad de poder, una voluntad que en algunos se encamina a obedecer $y$ en otros se encamina a mandar. Mediante la voluntad de poder se pueden crear ideales negativos o se puede violentar y organizar otros instintos. Para poner un caso concreto que Nietzsche ilustra en La genealogía de la moral: la crueldad es un instinto en el hombre, solo que se canaliza hacia diferentes lugares. El hombre que sacrifica su animalesco viejo yo, que se sacrifica a sí mismo, que se destruye; inevitablemente construye un valor: el altruismo. "Solo la mala conciencia, solo la voluntad de maltratarse a sí mismo proporciona el presupuesto para el valor de lo noegoísta" ${ }^{17}$. La negación de un instinto crea su contrario, el hecho de reprimir la natural crueldad hacia los demás, hace nacer la crueldad contra uno mismo: desinterés, autonegación, sacrifico de sí mismo: “(...) el placer que siente el desinteresado, el abnegado, el que se sacrifica a sí mismo: ese placer pertenece a la crueldad"18. Aquí entra en juego una visión ontológica del movimiento del mundo y del progreso del

acérrimo determinista. Para él libertad significaba seguir "la propia naturaleza", en cuanto esta naturaleza se hallaba en relación estrecha con toda la realidad.

${ }^{16}$ Al respecto cabe señalar la lectura de un relevante artículo de Pablo Martínez Becerra. Nietzsche y el despliegue de la libertad. Universidad Adolfo Ibáñez, Valparaíso. En: Revista Philosophica, 31/I (2007). En lo referente a sus tratamientos sobre la voluntad y la libertad, la lectura de Roux fue crucial. Hay que mencionar que es uno de los científicos más apreciados por Nietzsche, en realidad, su aprecio se manifestaba hacia la fisiología conocida por él hacia fines del siglo XIX. La relevancia de esto sobre el tema de la libertad radica en que Nietzsche apuntará a exaltar la idea de instinto (Instinkt) y de pulsión (Trieb) en la configuración elemental del ser humano, pues le interesará mostrar las influencias condicionantes de estos componentes al momento de actuar. La contraposición al modo idealista de concebir la voluntad es determinante. En efecto, Nietzsche quiere criticar la libertad de la voluntad como fundamento de la filosofía idealista y en pos de un abandono de esa filosofía; ese es el enorme desasimiento que tiene que atravesar quien por primera vez está sintiendo su libertad de espíritu frente al yugo de la metafísica (Véase el prólogo de Humano, demasiado humano I, aforismo 3).

${ }^{17}$ NIETZSCHE, F. La genealogía de la moral, op. cit., p. 113.

${ }^{18}$ Ibíd., p. 113. "Pero todas las finalidades, todas las utilidades son sólo indicios de que una voluntad de poder se ha enseñoreado de algo menos poderoso y ha impreso en ello, partiendo de sí misma, el sentido de una función; y la historia entera de una $\langle\operatorname{cosa}\rangle$, de un órgano, de un uso, puede ser así una ininterrumpida cadena indicativa de interpretaciones y reajustes siempre nuevos, cuyas causas no tienen siquiera necesidad de estar relacionadas entre sí, antes bien a veces se suceden y se relevan de un modo meramente casual". Ibíd., p. 100 
mundo, basado en la apropiación de un sentido de las cosas por parte de fuerzas dominantes, en detrimento de fuerzas subyugadas, justamente este proceso es activado por una voluntad de poder. Hay una actividad constante de ciertas fuerzas que imprimen un sentido cambiante a todo lo que acontece, este pensamiento se opone a un mecanicismo consistente en la mera adaptación de la vida a circunstancias externas a ella: el ideal igualitario o la espiritualización de las pasiones ${ }^{19}$.

La suspensión del juicio moral a favor de una mejor comprensión del mundo físico y de sus leyes es condición necesaria, según Nietzsche, para el creador de nuevas tablas de valor, en particular, para quienes se crean capaces de darse leyes a sí mismos. Entender que las acciones son movidas por otras energías (o impulsos) que no parten siempre de la capacidad racional del sujeto (mejor dicho aún: que la racionalidad no es más que un impulso entre varios en lucha) será la gran tarea que el pensador alemán defenderá mostrando la importancia de la física al momento de escudriñar sobre temas referidos a la psicología y a la moral ${ }^{20}$. En efecto, la resignificación que Nietzsche hace de la dicotomía libertad-naturaleza pasa por entender que no hay más que naturaleza y que, en todo caso, la libertad pasaría por encontrar un modo de dominio al interior de los propios impulsos naturales. No son más que ellos los que constituyen lo que en otro tiempo se denominó con el término "alma":

está abierto el camino que lleva a nuevas formulaciones y refinamientos de la hipótesis alma: y conceptos tales como «alma mortal» y «alma como pluralidad del sujeto» y "alma como estructura social (Gesellschaftsbau) de los instintos y afectos» desean tener, de ahora en adelante, derecho de ciudadanía en la ciencia ${ }^{21}$.

\subsubsection{Recepciones de Nietzsche sobre la libertad}

${ }^{19}$ Cfr. Ibíd., p 102. Es necesario entender que dichas fuerzas son parte de la física del mundo, son múltiples cuantos de energía que organizan el mundo. Al respecto, escribe Carlos Astrada: “(...) para Nietzsche no hay ninguna voluntad unitaria, sino puntuaciones de voluntad, las que constantemente incrementan o disminuyen y pierden su potencia. Estas unidades son 'cuantos' dinámicos que están en una relación de tensión con otros 'cuantos' dinámicos”. ASTRADA, C. Nietzsche. Almagesto, Bs. As., 1992 , p. 85.

${ }^{20} \mathrm{Al}$ respecto, véase el $\S 335$ de La ciencia jovial: “iArriba la física!”

${ }^{21}$ NIETZSCHE, F. Más allá del bien y del mal, op. cit., p. 34. 
Dentro de las recepciones actuales del pensamiento de Nietzsche, cabe mencionar tres autores que defienden la idea de una libertad en sentido positivo y creativo en el pensamiento de Nietzsche ${ }^{22}$ : Ken Gemes, Peter Poellner y John Richardson.

Desde la óptica de Ken Gemes, en el debate sobre la voluntad libre en Nietzsche debe distinguirse dos aproximaciones -que no siempre se presentan separadas sino que a veces confluyen-: en primer lugar, la cuestión del merecimiento, es decir, a quién se debe castigar y a quién recompensar. Y, en segundo lugar, la libre voluntad de actuar: la autonomía. Gemes argumenta que si bien Nietzsche deja de lado la responsabilidad merecida, en tanto responsabilidad moral del agente sí aboga por defender un tipo de responsabilidad, que es la responsabilidad de actuar, distinguiendo así una verdadera acción de un mero hacer ${ }^{23}$.

A su vez, Peter Poellner admite que la idea de libertad en Nietzsche debe ser pensada como un ideal normativo -o presupuesto- para un objetivo puntual que persigue su pensamiento: la construcción de una individualidad plena. El creador de valores debe tener, en cierto sentido, una voluntad libre. El autor dice que al formular su 'verdadera doctrina de la voluntad y la libertad', Nietzsche sugiere dos roles distintos: uno es el pensamiento de que la libertad propiamente dicha es constitutiva de ser una individualidad plena en sí misma, una persona en el sentido propio. $Y$ segundo, es la forma en la que el individuo puede crearse a sí mismo, dictarse sus propias leyes; es decir, ser un humano único y autónomo ${ }^{24}$. Todos tenemos voluntad, inclusive los humanos a quienes se niega que la tengan (los niños o los adictos, por ejemplo), pero lo que no todos tenemos es una voluntad libre, o lo que es lo mismo

\footnotetext{
${ }^{22}$ La bibliografía especializada sobre la cuestión es abundante, opto por la mención de estos autores por el acercamiento que tienen a lo sostenido a lo largo de este artículo. Lo que resulta de mayor interés en estos estudios anglosajones, es el foco que ponen en la idea de acción (agency) en Nietzsche; se trata de un concepto amplio pero que posibilita el ingreso a otros de mayor relevancia y complejidad: voluntad, libertad, "sí mismo".

23 "We shall argue that while Nietzsche rejects deserts responsibility he leaves room for a positive account of agency responsibility". GEMES, K. Nietzsche on free will, authonomy and the souvereign individual En: Nietzsche on Freedom and Autonomy. Edited by Ken Gemes and Simon May, Oxford University Press, 2009, p. 34.

${ }^{24}$ Cfr. POELLNER, P. Nietzschean Freedom. En: Nietzsche on Freedom and Autonomy. Edited by Ken Gemes and Simon May, Oxford University Press, 2009, pp. 151-153. Cabe mencionar que el miedo de los individuos de ejercer su propia voluntad llevó a los humanos a un declive de sus fuerzas y a la necesidad de sentirse seguros bajo la imposición de reglas impartidas por la religión.
} 
decir: una conciencia de sí mismo ${ }^{25}$ para poder responder desde sí mismo ${ }^{26}$. Según Poellner, la capacidad que Nietzsche recalca sobre la posibilidad que tienen algunos individuos de crearse a sí mismos, requiere una mínima habilidad para reflexionar sobre uno mismo y poder separarse de algunos impulsos ${ }^{27}$. Actuar bajo la luz de la propia razón y no meramente en concordancia con "La Razón", es decir, no universalizar los motivos de una acción singular, es la tarea que se presenta al espíritu libre. La pregunta que hay que hacerse es más que nada qué valoramos y no qué deseamos.

Por último, John Richardson (este es el autor que más tiene incidencia en nuestro objetivo) quiere mostrar que la crítica de Nietzsche a la libertad responde a formas pasadas de concebirla, y que su nueva concepción asume un nuevo tipo de libertad, de responsabilidad y de poder sobre uno mismo. Según Richardson, Nietzsche retoma ideas como libertad y responsabilidad y las hace suyas dándole su impronta, toma a la libertad como soberanía individual, como autonomía y como el alcance de un estado supra ético (más allá de la eticidad). El autor intenta demostrar la cercanía que tiene el concepto de libertad en la filosofía de Nietzsche con el de "poder", "sí mismo" y "responsabilidad", señalando la necesidad de entenderlos en relación. El individuo soberano se reconoce como un "sí mismo" y reconoce su poder sobre la naturaleza, sobre el destino y sobre los seres de corta voluntad; solo a partir de este reconocimiento puede sentirse libre. La responsabilidad puede manifestarse en los individuos soberanos en su forma más magnífica, en tanto dominio sobre sí mismos y sobre el destino. Es de utilidad para entender esto la insistente división nietzscheana

\footnotetext{
25 "It is plausible to adscribe experienced agency, and the corresponding level of subjectivity, even to very young children or to adults suffering from compulsive síndromes or strong addictions -individuals who, in Nietzsche term's, are 'slaves of momentary affect and desire' (GM II 3)”. Ibíd., p. 155.

${ }^{26}$ Aquí es importante atender a los aforismos 335 y 347 de La ciencia jovial, no puede eludirse la idea de una consciencia de sí mismo y una consecuente acción moral respetable en tanto y cuanto surja de un pleno conocimiento de sí mismo. "Quien todavía juzga $<<$ así tendrían que actuar todos en este caso $>>$, ni siquiera ha avanzado cinco pasos en el conocimiento de sí mismo: en caso contrario sabría que no hay acciones iguales y tampoco puede haberlas (...); que cada acción, vista ahora o retrospectivamente, es y sigue siendo un asunto impenetrable (...), la ley de su mecánica es indemostrable para cada caso particular”. NIETZSCHE, F. La ciencia jovial. Trad. José Jara, Monte Ávila, Venezuela, 1999, pp. 194195.

${ }^{27}$ Cfr. POELLNER, P. Nietzschean Freedom, op. cit., p. 156.
} 
entre los individuos capaces de hacer promesas y los que no lo son, apelando a la distinción, a la diferencia, a la jerarquía entre tipos de hombres ${ }^{28}$.

La libertad negada por el pensador alemán es, para Richardson, la libertad pura en sentido metafísico; pero hay una raíz biológica e histórica de la libertad que todavía no ha terminado de evolucionar. Por ello, la propuesta de Nietzsche apuntaría a resignificar o re-diseñar el concepto de libertad. En primer lugar, para naturalizar la libertad; esto se opone completamente a una libertad en sentido trascendental, pues se asume que es la capacidad de ciertos tipos de organismos, no de un sujeto puro. Richardson entiende que la libertad se transmite de organismo a organismo como un instinto o hábito. Y esta capacidad ha evolucionado mediante procesos biológicos y sociales: en efecto, el carácter acumulativo de esa historia evolutiva es la razón por la cual la libertad es indefinible. Pero la esperanza de Nietzsche residiría en reescribir y suprimir algo de lo que ha sido la libertad. Por otra parte, el re-diseño de la idea de libertad apunta a desmoralizarla. Este es el carácter principal de la transvaloración de todos los valores y significa entender la libertad en términos de impulsos, volviendo a entrar en contacto con nuestra animalidad; existen impulsos a los que le compete el control de lo que el organismo hace ${ }^{29}$. En este punto, Richardson cita el $\S 119$ de Aurora que resulta esclarecedor al respecto: "Por muy lejos que pueda llegar alguien al conocimiento de uno mismo, nada puede ser más incompleto que la imagen que formemos del conjunto de impulsos que constituyen su $\operatorname{ser}^{\prime \prime 30}$. Lo que pretende quien busca sentirse libre al momento de actuar es poder unificar esos impulsos para orientarlos en una misma dirección (más allá de que Nietzsche mismo diga que la mayoría de ellos son desconocidos para nosotros). En ese sentido, la libertad es nuestro impulso de sentir poder, un sentimiento de mando. Es importante resaltar que hablamos de un impulso que busca someter a otros impulsos; pues no se trata de una libertad plena y estable en el sentido moderno, no se trata de una razón superior que domina a los impulsos. Se trata de algo más tensional. Una guerra de instintos y el sentimiento fugaz de uno de ellos pretendiendo dominar a otros.

\footnotetext{
${ }^{28}$ Cfr. RICHARDSON, J. Nietzsche's Freedom. En: Nietzsche on Freedom and Autonomy. Edited by Ken Gemes and Simon May, Oxford University Press, 2009, pp. 127-129.

${ }^{29}$ Cfr. Ibíd., pp. 130-132

${ }^{30}$ NIETZSCHE, F. Aurora. Trad. Germán Cano, Biblioteca Nueva, Madrid, 2000, p. 135
} 
Lo que nos parece más esclarecedor del texto de Richardson es que entiende que para que pueda hablarse de libertad en sentido positivo en Nietzsche, primero el individuo debe alcanzar a ser un "sí mismo" y, para ello, es preciso que en el organismo se realice una unificación de los impulsos ${ }^{31}$. En este sentido, y siguiendo a Richardson, optaremos por interpretar la voluntad de poder como un instinto de libertad, el único capaz de posibilitar la creación de valores. Como ya anticipamos líneas arriba, la voluntad de poder es un instinto de libertad que está en todos, puede crear ideales positivos o negativos, pero lo que es seguro es que crea ${ }^{32}$. Existen dos afirmaciones de Nietzsche en torno a la voluntad que resultan fundamentales: 1) La voluntad es el signo distintivo del mando y 2) mandar es más difícil que obedecer. Estas dos afirmaciones de Nietzsche simplifican y sintetizan una compleja trama de críticas y un recorrido conceptual que el autor llevará a cabo para culminar en su propuesta supra-ética.

La mayoría de los autores que defienden una visión positiva de libertad en Nietzsche se apoyan en determinados pasajes claves ${ }^{33}$ que no dejan lugar a dudas de la persecución de un tipo de libertad en la acción, muy poco asequible para muchos, pero alcanzable para algunos individuos dispuestos a la superación de la decadencia propia tanto de la metafísica como de la moral. De hecho, el mayor coto que hombre occidental ha encontrado para poder desplegar libremente sus fuerzas ha sido el error metafísico de pensar que sus acciones eran guiadas por un fin universal. En efecto, habrá una forma en la que el individuo pueda ser soberano de sus propias virtudes y pueda entenderlas a estas para sí mismo, de forma singular.

Ahora bien: ¿cuál es la manera que encuentra el individuo de practicar una virtud singularizada, libre del manto de la cultura y de la moralidad dominantes? Es esta una de las preguntas rectoras de este escrito y que se buscará responder a continuación.

\section{4. "La virtú sin moralina”}

\footnotetext{
${ }^{31}$ Cfr. RICHARDSON, J. Nietzsche's Freedom, op. cit., p. 133.

${ }^{32}$ Véase $\$ 18$ de Genealogía de la moral, segundo tratado.

${ }_{33}$ Especialmente pueden destacarse el $\$ 347$ de La ciencia jovial y el $\S 2$ del segundo tratado de La genealogía de la moral.
} 
La concepción de Nietzsche sobre la virtud es polivalente, más allá de las críticas hacia sistemas éticos como el socrático-platónico, el cristiano, el kantiano o el utilitarista, existe una visión afirmativa o propositiva que se vincula con la antigua concepción de la areté como excelencia individual, sin connotaciones morales o intelectuales, sino heroicas. La excepción griega negativa fue Sócrates ${ }^{34}$, quién asoció a la virtud con la razón, algo muy alejado del concepto homérico. Lo cierto es que Nietzsche vio positivamente el hecho de poseer virtudes propias, que se distancien de las antiguas virtudes cardinales o de las virtudes que siempre han pretendido el valor universal. En cambio, las virtudes perseguidas por Nietzsche se reconocerían en el sello de su singularidad, serían inexpresables, sin nombre, únicas. Además, antes que contraponerse a las pasiones (idea cristianizada de la virtud moral), surgirían de las pasiones mismas, serían el producto de lo que ya se ha denominado como sublimación de las pasiones ${ }^{35}$. Las afirmaciones de Nietzsche sobre virtudes específicas (valentía, honestidad ${ }^{36}$ ) tienen que considerarse haciendo la reserva de que estas, por su singularidad, son en el fondo inexpresables y sin nombre. Pero, sobre todo, son terrenales, es decir, apuntan a tener un trato intenso con este mundo ${ }^{37}$. La virtud no puede nacer de otro lugar que no sea la pasión, es la transformación de una pasión o, si se quiere, su ennoblecimiento:

En otro tiempo tenías perros salvajes en tu mazmorra: pero al final se transformaron en pájaros y en amables cantoras. De tus venenos has

\footnotetext{
34 "Intento comprender de qué idiosincrasia procede la equivalencia socrática de razón=virtud=felicidad: la equivalencia más estrafalaria que existe y que tiene en su contra especialmente a todos los instintos de los antiguos helenos". NIETZSCHE. El crepúsculo de los ídolos. Trad. Daniel Gamper, biblioteca nueva, Madrid, 2002, p. 47.

${ }^{35}$ Confrontar en el pasaje De las alegrías y las pasiones, de Así habló Zaratustra.

36 "La honestidad, suponiendo que ella sea nuestra virtud, de la cual no podemos desprendernos nosotros los espíritus libres - bien, nosotros queremos laborar en ella con toda malicia y con todo amor y no cansarnos de <<perfeccionarnos〉> en nuestra virtud, que es la única que nos ha quedado: ique alguna vez su brillo se extienda (...) sobre esta cultura envejecida y sobre su obtusa y sombría seriedad!". NIETZSCHE, F. Más allá del bien y del mal, op. cit., p. 173.

37 "Una virtud terrena es la que yo amo: en ella hay poca inteligencia, y lo que menos hay es la razón de todos". NIETZSCHE, F. Así habló Zaratustra. Trad. Andrés Sánchez Pascual, Alianza, Madrid, 2004, p. 67.
} 
extraído tu bálsamo, has ordeñado a tu vaca Tribulación, - ahora bebes la dulce leche de sus urbes ${ }^{38}$.

Más adelante, en el mismo pasaje, Nietzsche afirma que lo mejor que puede pasarle a un individuo es tener una sola virtud, pues el hecho de tener más de una significa la guerra entre ellas, es de allí de donde puede surgir algo malo, es a causa de la lucha entre las propias virtudes que el hombre puede perecer, pues cada virtud demanda toda la fuerza hacia sí. Ahora bien, el hombre es algo que debe perecer, que debe ser superado, por ello, el camino del amor a las propias virtudes es el indicado para quien persiga la meta de la auto-superación ${ }^{39}$. La provocadora idea de ser víctimas de nuestras virtudes es recurrente en Nietzsche y adquiere diversos matices, uno de ellos refiere a la peligrosidad ínsita que conlleva el cultivo de las virtudes: una recaída en la moral; mejor dicho quizá, en una moral esclavizante. El § 227 de Más allá del bien del mal resulta esclarecedor para entender ese fino límite entre una virtud deseosa de superación y aquella que se transforma en una regla, paralizando al hombre. Los espíritus libres, aquellos a los que Nietzsche llamó los últimos estoicos, deben permanecer duros ante el peligro de que sus virtudes se santifiquen, cooptando el camino creador: "Nuestra honestidad, (...) icuidemos de que no se convierta en nuestra vanidad, en nuestro adorno y vestido de gala, en nuestra limitación, en nuestra estupidez! ${ }^{40}$. En la ciencia jovial Nietzsche ya había hablado de <<almas más finas $\gg$, cuya virtud consiste en una suspicacia en sí mismas y en la virtud, evitando la tendencia sacerdotal de depositar fe en una virtud y así adquirir bienaventuranza ${ }^{41}$; con esto, ponía de manifiesto la paradoja que encierra hablar de virtud en el proceso de auto-superación de la moral.

Aunque ciertas virtudes merezcan ser nombradas, no se trata de hacer un listado de virtudes para todos los hombres, resulta difícil pensar algo así porque sería negar que Nietzsche es un pensador que atiende a la singularidad en innumerables

\footnotetext{
${ }^{38}$ Ibid., p. 68.

39 "El hombre es algo que tiene que ser superado: y por ello tienes que amar tus virtudes, -pues perecerás a causa de ellas". Ibid., p. 69.

${ }^{40}$ NIETZSCHE, F. Más allá del bien y del mal, op. cit., p. 174.

${ }^{41}$ Confrontar con el aforismo 214 de La ciencia jovial.
} 
sentidos. Uno de ellos es el que se refiere a la virtud; asume positivamente a una virtud que nadie tiene en común con otro, una virtud singular, sin moralina, liberada de toda connotación intelectual, moralista o eudaimonista. Esto puede admitirse atendiendo al § 120 de La ciencia jovial, denominado la salud del alma:

Para determinar lo que haya de significar salud para tu propio cuerpo, todo depende de tu meta, tu horizonte, tus fuerzas, tus impulsos, tus errores y, especialmente, de los ideales y fantasmas de tu alma. Por eso, existen incontables saludes del cuerpo; y mientras más se permita nuevamente alzar su cabeza al hombre individual e incomparable, mientras más se desaprenda el dogma de la <igualdad de los hombres>, más han de perder también nuestros médicos el concepto de una salud normal, junto al de una dieta normal y curso normal de la enfermedad ${ }^{42}$.

Esto mismo puede aplicarse a la virtud entreviendo el rechazo que el autor sostuvo sobre los modos universales de conducirse éticamente; pues se supone que existen individuos, pero no un Yo que esté por encima como modelo de sujeto, así como tampoco existe un Deber que se ubique como rector de las formas que cada uno tiene de manejar sus pasiones. Este es el primer paso para el rastreo y la comprensión de un tipo de ética en el pensamiento de Nietzsche: lo bueno no se regirá más por un principio rector para todos los hombres por el hecho de pertenecer al concepto Humanidad, sino que lo bueno será lo que resulte más eficaz al momento de conducir a una pasión desmedida para transformarla en virtud.

A partir de entender lo bueno como un sentimiento de poder, de vigor, de eficacia, resulta legítimo que el virtuoso sea el que puede superar una resistencia ${ }^{43}$ externa o interna y nada más que ello; con esto pretende despegarse de un tipo de

\footnotetext{
${ }^{42}$ NIETZSCHE, F. La ciencia jovial, op. cit., p. 114.

43 "¿Qué es felicidad? El sentimiento de que el poder crece, de que una resistencia queda superada. No apaciguamiento, sino más poder; no paz ante todo, sino guerra; no virtud, sino vigor (virtud al estilo del Renacimiento, virtú sin moralina)." NIETZSCHE, Friedrich, El Anticristo. Trad. Andrés Sánchez Pascual. Alianza, Madrid, 2008, p. 32.
} 
virtud que solo pueda entenderse respondiendo al deber, al pecado ${ }^{44} \mathrm{o}$ a la utilidad de la mayoría. En contraposición a la forma ascética de virtud, Nietzsche invoca un concepto de virtud que tenga su origen en una riqueza desbordante y apasionada que no realice cálculos sobre ventajas y desventajas ${ }^{45}$. En el pasaje llamado Von der schenkenden Tugend (de la virtud que hace regalos), Zaratustra se pregunta cómo es que el oro, siendo raro e inútil, llegó a ser un valor supremo; esta es una coordenada importante para el rescate de virtudes que no deban responder al criterio de la masividad y tampoco de la utilidad:

Rara es la virtud más alta, e inútil, y resplandeciente, y suave en su brillo: una virtud que hace regalos es la virtud más alta (...) En verdad, semejante amor que hace regalos tiene que convertirse en ladrón de todos los valores; pero yo llamo sano y sagrado a ese egoísmo ${ }^{46}$.

Seguidamente, en el mismo pasaje, Nietzsche menciona ciertas afirmaciones claves y que constituyen la forma más positiva-propositiva en su obra al hablar del origen de las virtudes: una virtud nace de un corazón que hierve ancho y pleno, que constituye tanto una bendición como un peligro para quienes habitan sus orillas (lo que da cuenta del carácter polivalente de la virtud -un carácter impensable para las éticas clásicas-); se debe estar por encima de la alabanza y de la censura (más allá del bien y del mal), dando órdenes a las cosas (voluntad de forjar un destino propio), despreciar lo agradable y la cama blanda (influencia estoica), no tener más que una sola voluntad, llamada necesidad, un nuevo bien y un nuevo mal, poder, un pensamiento dominante ${ }^{47}$.

Sin el propósito de desarrollar la temática del egoísmo, es preciso entender la relación que Nietzsche establece entre virtud y egoísmo para evitar interpretaciones

\footnotetext{
44 “Ay, esto es lo que me aflige: mentirosamente se ha situado en el fondo de las cosas recompensa y castigo -y ahora también en el fondo de vuestras almas, virtuosos". NIETZSCHE, F. Así habló Zaratustra, op. cit., p. 147.

${ }^{45}$ NIEMEYER, C. Diccionario Nietzsche. Conceptos, obras, influencias y lugares. Edición española a cargo de Germán Cano, Biblioteca Nueva, Madrid, 2012, p. 529.

${ }^{46}$ NIETZSCHE, F. Así habló Zaratustra, op. cit., p. 122-123.

${ }^{47}$ Cfr. Ibíd., p. 124.
} 
precipitadas. La concepción utilitarista fue una de las encargadas de separar la virtud del egoísmo y de asumir que el virtuoso es tal en tanto y en cuanto sea funcional a la sociedad. De esta manera, el individuo termina siendo víctima de sus propias virtudes porque la sociedad lo explotará hasta dañar su salud. No es importante la conservación de un virtuoso, lo importante es que haya dado todo para la conservación de su comunidad. "El elogio del virtuoso es el elogio de algo que daña lo privado -el elogio de instintos que quitan al hombre su más noble egoísmo y la fuerza para el cuidado de sí mismo" ${ }^{\prime 8}$. Nietzsche demuestra que las virtudes enaltecidas por la sociedad industrial son la obediencia, la castidad, la piedad y la justicia, todas ellas orientadas al sacrificio del individuo y en beneficio de la conservación del sistema institucional.

La apelación constante de Nietzsche de una búsqueda personal de la virtud, es decir, del ir al encuentro con lo singular de una virtud propia, responde al deseo irrefrenable de superación del nihilismo europeo. De hecho, en el § 214 de Más allá del bien y del mal el propio autor se afirma como uno de los últimos herederos de la buena conciencia europea, de las "candorosas y macizas virtudes por las cuales honramos a nuestros abuelos ${ }^{49 \prime}$. La pretensión de Nietzsche pasa por encontrar un tipo humano que pueda cultivar su propia virtud, lo que significa que esta tiene que estar en armonía completa con la naturaleza particular del individuo, con sus impulsos básicos, con su voluntad de poder. La virtud, de hecho, debería ser una respuesta a los impulsos destructivos del ser humano, transformados, sublimados en formas de actuar honorables: "-nosotros, si es que debiéramos tener virtudes, tendremos presumiblemente solo aquellas que hayan aprendido a armonizarse de manera óptima con nuestras inclinaciones más secretas e íntimas, con nuestras necesidades más ardientes $^{\prime \prime 50}$. ¿Qué conlleva esta apuesta de Nietzsche? Pues, en principio, la no asociación virtud-bueno, la aceptación de que el virtuoso será quien asuma lo que hay de necesario en sus actos y los acepte con las desdichas y alegrías que puedan acarrear. En este esquema no hay lugar para el arrepentimiento, sí para el amor fati. Aceptar lo trágico en la vida, la dialéctica entre alegría/tristeza, apolíneo/dionisíaco,

\footnotetext{
${ }^{48}$ NIETZSCHE, F. La ciencia jovial, op. cit., p. 43.

${ }^{49}$ NIETZSCHE, F. Más allá del bien y del mal, op. cit., p. 161.

${ }^{50}$ Ibídem.
} 
significa revalorizar lo malo y lo feo en el orden de la existencia, significa exaltar todos los órdenes de la existencia, haciendo de la necesidad una virtud ${ }^{51}$. La re-consideración de lo doloroso, de lo feo, de lo incómodo, puede ser un punto de partida para entender las bases de las nuevas creaciones. Es decir, de los valores nuevos en tablas nuevas, del nacimiento de nuevas virtudes que dejen atrás la moral decadente atestada por el altruismo y la compasión. Hay un enorme problema que Nietzsche detecta como producto de lo que llama nihilismo, y es que le han suprimido el dolor a la existencia (eso es lo que hizo el capitalismo contemporáneo ${ }^{52}$ ) y entonces ya no hay posibilidad de crear en esas condiciones, el hombre tiene que seguir manifestándose en su plenitud (dolor y placer) para poder crear. Lo que significa también -luego de haber comprendido lo que significa la voluntad de poder-crearse a sí mismo, recrearse. En la filosofía de Nietzsche la virtud por excelencia es sin dudas la creación.

\subsection{El crear (schaffen) - la voluntad de poder como creación}

\footnotetext{
${ }^{51}$ Vattimo afirma que el ultrahombre hace de la necesidad una virtud y que por allí justamente pasa su excelencia.

52 Ciertamente, una de las grandes "seguridades" del mundo moderno es el derecho a tener una vida digna por medio del trabajo; aquí, una vez más, brota una hipocresía moral, porque aquello que pretende hacer libres a los hombres no hace más que esclavizarlos. Nietzsche, en su Ensayo sobre los griegos, admite una idea sobre la esclavitud de talante aristocrática. Ser esclavo es una palabra que la modernidad ha vituperado, cuando en realidad los hombres modernos son esclavos del trabajo y del ideal de dignidad humana. Hay una contraposición que el autor realiza entre los modernos (quienes identifican la dignidad del hombre con la dignidad del trabajo) y los griegos (para quienes el hombre y el trabajo son vergonzosos, porque se trabaja sólo para la conservación). Por eso concluye Nietzsche que del trabajo no puede nacer ningún artista: "El trabajo es una vergüenza porque la existencia no tiene ningún valor en sí, pero si adornamos esta existencia por medio de ilusiones artísticas seductoras, y le conferimos de este modo un valor aparente, aun así podemos repetir nuestra afirmación de que el trabajo es una vergüenza, y por cierto en la seguridad de que el hombre que se esfuerza únicamente por conservar la existencia, no puede ser un artista”. NIETZSCHE, F. Ensayo sobre los griegos. Trad. Felipe González Vicen, Godot, Bs. As., 2013, p. 8. Pero la realidad es que todas las nominaciones hasta ahora establecidas, todo el lenguaje que asimilamos hasta la modernidad son conceptualizaciones hechas por esclavos. Una dignidad elevada para el trabajo es la resultante de la creación y no al revés. Uno debe doblegarse al trabajo si es que tiene espíritu abolengo, sólo si la creación poética/artística lo requiere. O por o menos es la idea que el pensador alemán quería seguir de los griegos. Cfr. Ibíd, p. 10. Esta verdad es pesada de aceptar en tanto que supone la necesidad de la esclavitud para la mantención de la cultura: "Lo que en esta terrible constelación de cosas quiere vivir, o mejor, debe vivir, es, en el fondo, un trasunto del entero contraste primordial que a nuestros ojos terrestres y mundanos debe aparecer insaciable apetito de la existencia y eterna contradicción en el tiempo, es decir, como devenir. Cada momento devora al anterior, cada nacimiento es la muerte de innumerables seres, engendrar la vida y matar es una misma cosa”. Ibíd, p. 13.
} 
Varios son los lugares del Zaratustra donde encontramos expresado el nihilismo positivo o la voluntad de creación: De las mil metas y de la única meta ${ }^{53}$, De la redención, De las viejas y de las nuevas tablas, Del camino del creador y Las islas afortunadas.

Si hablamos de voluntad de poder como creación hablamos de la voluntad de poder propia del Übermensch. Bien lo recalca Vattimo:

\begin{abstract}
Para el ultrahombre, la voluntad de poder es, ante todo, voluntad de superación, amor de la aventura, capacidad de despedirse, la destrucción que está necesariamente implícita en cada reajuste nuevo y más rico del modo de relacionarse, teórica y prácticamente, con el mundo. ${ }^{54}$
\end{abstract}

Por ello es que para Nietzsche el artista ya no constituye un ideal a seguir como sujeto máximo de la creación. ${ }^{55}$ La creación máxima que anhelaba Nietzsche hasta su tiempo era la del Übermensch. Pero, ¿qué debía suceder para que esto llegue a curso? Debía haber primero una desvalorización de los antiguos valores, más allá de que ello lleve pesar y desasimiento, de hecho, en esto consiste la dureza del creador, quien tendría como criterio a la intensificación del poderío vital para saber que aquello creado era algo nuevo. Si el poder crece con la creación, podría hablarse del triunfo de la afirmación y de la actividad. Pero, ¿ cómo confrontar esta idea con aquellas lecturas que sostienen el triunfo de las fuerzas reactivas? Cuando Deleuze recalca que uno de los sentidos fuertes que adquiere la jerarquía en Nietzsche es el triunfo de las fuerzas reactivas por sobre las activas, pone en cuestión la posibilidad de concreción del nacimiento de los espíritus libres o, mejor dicho, de su victoria (recordando que, para este autor, el esclavo no es el menos fuerte sino aquel que está separado de sus

\footnotetext{
53 "Valorar es crear: joídlo creadores! El valorar mismo es el tesoro y la joya de todas las cosas valoradas". NIETZSCHE, F. Así habló Zaratustra, op. cit., p. 100; "siempre aniquila el que tiene que ser un creador". Ibid., p. 101. La única meta está entre comillas porque se trata de alguna meta, es decir que la humanidad nunca tuvo una meta, un sentido. O, mejor dicho, su sentido fue la nada. Es lo que afirma la mentada frase de La genealogía de la moral: el hombre prefirió querer la nada a no querer.

${ }^{54}$ VATTIMO, G. El sujeto y la máscara, op. cit., p. 322.

${ }^{55}$ Ver fragmento póstumo de 1883, 16 [14]- Aquí se pregona la idea de una superación del artista y de la obra de arte clásicos. El artista ya pasa a ser una etapa previa; no se pretende solo nuevos valores, sino que se pretende la creación del Übermensch, y el requisito máximo para esto es la muerte de Dios y el nihilismo.
} 
fuerzas). Si tomamos las tres características elementales de la fuerza activa según Deleuze (fuerza plástica dominante, fuerza que va hasta el final de lo que puede y fuerza que afirme su diferencia ${ }^{56}$ ), puede conjeturarse que aquellos espíritus disruptivos que Nietzsche contrapuso en Humano, demasiado humano frente a las comunidades cerradas son fieles representantes de fuerzas activas. Pues, se trata de espíritus plásticos que afirman su diferencia y quebrantan valores establecidos. Pero, ante todo, se trata de hombres que se toman a sí mismos como experimentos, que ven en sí mismos la posibilidad de devenir en nuevas formas de experimentar-se, tal como afirmaba Vattimo. Asumido ya el abandono de la capacidad deliberativa de la voluntad, cabe buscar nuevas experiencias en el cuerpo, nuevas posibilidades del cuerpo. "Se hacen cientos de miles de experimentos para modificar la alimentación, el modo de habitación y de vida del cuerpo: la conciencia y las estimaciones de valor en él, todas las especies de placer y displacer son indicios de estas modificaciones y experimentos. Al fin no se trata en absoluto del hombre: él debe ser superado" ${ }^{57}$. Pero, como veremos, estos nuevos experimentos no tienen lugar si no se admite la posibilidad de redimir los sentidos anteriores que los humanos le hemos dado al cuerpo, solo la voluntad redentora del Übermensch es capaz de semejante tarea.

Retomando la cuestión de la voluntad de poder creadora, Gianni Vattimo admite que ella tiene que interpretarse desde varios ángulos ${ }^{58}$. Sin embargo, uno de los sentidos que aparece con mayor fuerza en la obra del filósofo italiano es el sentido de redención de la voluntad de poder, es decir, la posibilidad de liberarse del peso del pasado, desarrollando nuevas formas simbólicas. Esta característica sería propia del Übermensch ${ }^{59}$. Sin embargo, el propio Vattimo dice que la voluntad de poder no puede pensarse solo como característica del Übermensch sino que es afín a todo hombre en tanto que este es alguien que realiza valoraciones, estableciendo una jerarquía axiológica $^{60}$. La interpretación de Vattimo apunta a resaltar una cualidad elemental de

\footnotetext{
${ }^{56}$ Cfr. DELEUZE, G. Nietzsche y la filosofía. Trad. Carmen Artal, Anagrama, Barcelona, 2008, p. 89.

${ }^{57}$ DELEUZE, G. Nietzsche. Trad. Isidro Herrera y Alejandro del Río, Arena, Madrid, 2006, p. 52.

${ }^{58}$ VATTIMO, G. El sujeto y la máscara, op. cit., p. 311.

${ }^{59}$ Cfr. Ibíd, p. 315.

60 "Voluntad de poder equivale a ficción teórica y científica de la realidad. El hombre no ha encontrado fuera de sí los órdenes dentro de los que aprehende y trata la realidad, es él quien los ha puesto desde el principio; y este poner es voluntad de poder”. Ibíd, p. 315.
} 
la voluntad de poder que venimos decodificando: la creación. Ya sea para amar y obedecer viejas tablas de valor como para establecer nuevas, la voluntad de poder crea por el hecho mismo de valorar. Pero Vattimo quiere resaltar lo que Nietzsche llamó nueva voluntad de poder, es decir, aquella que elimina las tablas valores trascendentes/imperecederos en pos de una nueva meta terrena que le dé un sentido a la humanidad. En otras palabras, la creación de una meta que le haga salir del nihilismo; solo cuando la humanidad pueda obedecerse a sí misma podrá gozar de esta condición no-nihilista ${ }^{61}$.

Vattimo cree, en líneas generales, que la voluntad de poder se concibe siempre como la esencia de toda la historia pasada y futura del hombre. Sostiene que esa noción se presentó, alternativamente, como determinación de la actitud con que el Übermensch se impone a la naturaleza o a sí mismo, o también como la esencia misma de la decisión eternizante que, según Zaratustra, redime las cosas de la casualidad atribuyendo un sentido incluso al pasado, o que en general confiere al devenir el carácter del ser. El hombre creador es también un destructor, destruye el mundo simbólico del pasado para crear uno nuevo y liberarse del viejo, en este sentido la voluntad de poder positiva consiste en liberar de la masa. Vattimo recuerda la distinción nietzscheana entre una voluntad de poder antigua (orden de valoraciones fijados por los pueblos y propia del hombre común ${ }^{62}$ ) y una suprema (producción autónoma de símbolos y valores), sólo con este segundo tipo la humanidad puede poseerse a sí misma.

Vattimo acierta, según nuestra opinión, con resaltar enfáticamente la distinción entre una voluntad de poder antigua y una nueva, pues Nietzsche mismo le da suma importancia a ello en De la superación de sí mismo, cuando dice: "Vuestra voluntad y vuestros valores los habéis colocado sobre el río del devenir; lo que es creído por el pueblo como bueno y como malvado me revela a mí una vieja voluntad de poder" ${ }^{63}$. También Jaspers recuerda el mismo pasaje cuando trata el tema de la obediencia:

\footnotetext{
${ }^{61}$ Confrontar con el pasaje De la superación de sí mismo, de Así habló Zaratustra.

${ }^{62}$ En Así habló Zaratustra, Nietzsche dice que los "sapientísimos" tienen la voluntad de hacer pensable todo, quieren crear un mundo ante el cual se puedan arrodillar y en cual se sientan seguros, esa es su voluntad de poder negativa.

${ }^{63}$ NIETZSCHE, F. Así habló Zaratustra, op. cit. p. 174.
} 
“...en todo lugar en que encontré seres vivientes oí hablar también de obediencia. Todo ser viviente es un ser obediente" ${ }^{64}$. En el aforismo 259 de Más allá del bien y del mal, Nietzsche afirma algo que los autores mencionados trataron, especialmente Jaspers, al decir que se debe entender todo lo que existe como voluntad de poder. Dice Nietzsche: “...tendrá que ser la encarnada voluntad de poder, querrá crecer, extenderse, atraer a sí, obtener preponderancia, - no partiendo de una moralidad o inmoralidad cualquiera, sino porque vive, y porque la vida es cabalmente voluntad de poder $^{\prime 65}$.

La voluntad en el Übermensch nunca deja de ser voluntad de engendrar, de crear. Voluntad de superación y de liberación. "Todo lo sensible en mí sufre y se encuentra en prisiones: pero mi querer viene siempre a mí como mi liberador y portador de alegría. El querer hace libres: esta es la verdadera doctrina acerca de la voluntad y la libertad así os lo enseña Zaratustra". ${ }^{66}$ El acto creador no está reservado a cualquier individuo. Para consumar la creación deben darse ciertas condiciones: soledad, inocencia, libertad de actuar ${ }^{67}$.

El creador hace de su voluntad su propia ley y se somete a ella, transformándola en destino. El espíritu libre es el único espíritu que puede tener un Übermensch, mientras más quiere más libre se encuentra. Como la liberación es un proceso que se da poco a poco y no un destello que hace pasar de un estado a otro bruscamente, y como es algo que hay que mantener día a día y cultivar, es por eso que el Übermensch vive creando y vive queriéndose, amándose a sí mismo y a lo que

\footnotetext{
${ }^{64}$ Ibídem.

${ }^{65}$ NIETZSCHE, F. Más allá del bien y del mal, op. cit. p. 222.

${ }^{66}$ NIETZSCHE, F. Así habló Zaratustra, op. cit. p. 87.

${ }^{67}$ Pocas veces Nietzsche emite descripciones tan sintéticas refiriéndose a los hombres preparatorios, a los espíritus libres como lo hace en el aforismo 283 de La ciencia jovial, pero lo dicho en este aforismo bien podría aplicársele a la figura del Übermensch. Se trata del hombre que, según el autor, no podría surgir de las grandes urbes actuales (debido al tipo de cultura impulsado allí): "hombres que saben ser silenciosos, solitarios, decididos, felices y constantes con actividades imperceptibles; hombres que por inclinación interior buscan en todas las cosas lo que en ellas haya de superarse; hombres cuya alegría, paciencia, sencillez y desprecio por las grandes vanidades les es tan propia como la generosidad en la victoria y la indulgencia frente a las pequeñas vanidades de todos los vencidos; hombres con un juicio agudo y libre sobre todos los vencedores y sobre la porción de azar que hay en toda victoria y fama; hombres que tienen sus propias fiestas, sus propios días de trabajo, sus propios períodos de duelo, habituados y seguros al mandar e igualmente dispuestos a obedecer cuando corresponde, en uno y otro, con el mismo orgullo y sirviendo por igual a su propia causa: ¡Los hombres en mayor peligro, los hombres más fecundos, los hombres más felices!”. NIETZSCHE, F. La ciencia jovial, op. cit., p. 164.
} 
crea $^{68}$. Si alguien no quiere, no crea, y si no ama lo que crea, entonces estamos frente al signo más fuerte de decadencia. Por eso, el Übermensch tiene que enfrentarse al pasado sin resentimientos, tiene que recrearlo cambiándole el sentido, pero teniendo en cuenta el carácter perspectivista: "todo sentido es creación provisional sin garantías ni seguridades y toda creación responsabilidad y riesgo sin juicio final” ${ }^{69}$.

En definitiva, la última categoría más importante para entender la ética nietzscheana y que es sobre la que venimos hablando es el amor fati. Amar el destino, en los términos del Übermensch, no puede ser otra cosa que recrearlo, dándole al pasado una nueva perspectiva, reinterpretando toda culpa y resentimiento. Es una forma de perdonar las propias acciones de los hombres que lo han llevado a la decadencia (perdonar el ascetismo, por ejemplo). El único que puede ser responsable para dar estos nuevos sentidos es el Übermensch, él es quien puede hacer retornar el pasado con un sentido nuevo. Esta es una forma de adquirir autonomía respecto del propio pasado. Así, podemos afirmar con Peter Sloterdijk que "la voluntad de aceptar la propia culpabilidad -la variante psiconáutica, por así decirlo, del amor fati- (...) cesa

\footnotetext{
${ }^{68}$ Como bien señala Víctor Massuh, crear "no solo significa un rechazo del rebaño, del orden compulsivo de la repetición, sino de todo aquello que no comporta la presencia misteriosa de este acto mediante el cual el creador engendra formas sin apelar a ningún modelo preestablecido. Se trata de un acto que no acepta el mandato de la razón, la exigencia de la comunidad, ni el imperativo ético de una acción desinteresada y piadosa" MASSUH, V. Nietzsche y el fin de la religión. Editorial Sudamericana. 1985, p. 109. Para esto es necesario un tipo de soledad. La soledad implícita de un instante en que el hombre siente de manera supra-histórica y admite que de él puede nacer una forma totalmente nueva de relacionarse con el mundo; no hay en este instante ningún recordar, ninguna conciencia moral que actúe de condición. Por ello la soledad implica un tipo de inocencia en el crear: "El acto creador es vivido por el hombre superior a partir de la totalidad de sí mismo: de lo bueno y de lo malo; aunque incluya la crueldad será un acto triunfal nunca manchado por la culpa o el remordimiento". Ibíd., p. 110. La creación no puede venir sino es de un instante libre de la voluntad. "transformar todo fue en un así lo quise"... "La voluntad se da como juego supremo, como la fuerza que mueve los mundos y hace posible que el creador condicione la realidad y le imprima su sello. Ella hace posible que el creador proyecte sobre el mundo su propio señorío.” Ibíd, p. 111.

${ }^{69}$ María Jesús Mingot Marcilla. El vértigo del Amor Fati: Libertad y Necesidad en Nietzsche. En: Revista de Filosofía. Vol. 35 núm. 1 (2010), p. 74. La idea de cambio de sentido como redención del pasado también fue asumida por Herbert Marcuse, quien afirma la posibilidad de liberar al hombre de su herencia arcaica asumiendo el tiempo cíclico y entendiendo que los sentidos del pasado tienen que retornar mutados, esta es la única forma de liberarse de la moral opresiva: "Para Nietzsche, la liberación depende de la reversión del sentido de culpa; la humanidad debe llegar a asociar la mala conciencia no con la afirmación sino con la negación de los instintos de la vida, no con la rebelión contra sus ideales represivos sino con su aceptación". MARCUSE, H. Eros y civilización. Trad. Juan García Ponce, Ariel, Bs. As., 1985, p. 121.
} 
de buscar culpables; renuncia a existir como un ser teórico y a justificarse con orígenes ausentes o causas imaginarias" ${ }^{\prime 70}$.

\subsection{Conclusiones}

El pensamiento directriz de este escrito fue la reconstrucción ética concebida por Nietzsche a partir de la autonomía del espíritu en términos de voluntad de poder. Semejante reconstrucción tuvo que hacer frente a las acusaciones del propio autor respecto de las posturas que han defendido una libertad metafísica de la voluntad, desprendida de todo factor material o histórico. Nietzsche no podía asumir la idea de autonomía kantiana porque esta admitía una esfera de la vida humana que trascendía la realidad natural. La pura espontaneidad como causa del movimiento de las acciones humanas era la carta más fuerte que el filósofo de Könisberg apostaba para sostener su concepción de la libertad de la voluntad, pero este tipo de autonomía era inconcebible para Nietzsche desde el momento en que él afirma que la voluntad es un hecho complejo y en íntima conexión con las causas naturales. Para el pensamiento nietzscheano no hay un sujeto volente y libre y una naturaleza necesaria que se le opone; se desmantela la clásica oposición -enfatizada por Kant- entre necesidad y libertad porque la necesidad no responde a un mecanicismo de la naturaleza, sino a la expresión de la actividad de los impulsos en el organismo y la relación de este con otros organismos vivos o inertes. Entonces, no puede haber separación del sí mismo con respecto a los impulsos, estos lo constituyen y la libertad no tiende a una emancipación del plano instintivo sino a la aceptación de la misma actividad propulsora de los instintos. Esto sucede porque el concepto de libertad asume otro sentido, quedando ligada a la voluntad de poder. Los instintos pueden ser unificados, reconducidos, educados mediante la fuerza activa de la voluntad de poder, pero no pueden ser olvidados, negados o extirpados porque la constitución humana depende de ellos. En efecto, la ética de los actos humanos, o si se quiere, las formas de proceder en la vida, tienen que estar ligadas a las pasiones de la propia naturaleza.

\footnotetext{
${ }^{70}$ SLOTERDiJK, P. El pensador en escena. Trad. Germán Cano, Pre-textos, Valencia, 2000, pp. 181182. Es lo que Sloterdijk, líneas más adelante, identificará con una autonomía dionisíaca.
} 
Si la imposición de sentidos es el acto ético por excelencia, la imposición de los sentidos del Übermensch para sí mismo -la creación- representa un tipo de ética. Pero la particularidad de esta ética es que anuncia sentidos no perdurables, nacidos a partir de la propia acción y no a partir de principios. De hecho, si hay una imposición de sentidos para otros, no se trata de una imposición calculada sino inconsciente. Si tomamos al Übermensch como un resultado posible de la existencia de espíritus libres y entendiéndolo también a él como un espíritu libre, no puede decirse que practique una autoconciencia ni que calcule sus acciones. Eso sería transformar la acción del Übermensch en una acción propia del sujeto de la Modernidad. Muy por el contrario, el Übermensch estaría libre también de las ataduras de la conciencia y, como bien afirma Vattimo, estaría desvinculado del mundo de la ratio.

La suprema fórmula superhumana del Amor Fati es la que enseña a recrear el pasado y la que logra desembarazar a la voluntad de la culpa y el resentimiento propias del hombre reactivo. Solo amando lo que el hombre ha sido permitirá dar cabida a lo nuevo, lo que muestra -una vez más- la apuesta nietzscheana por no escindir al individuo de su hado y de las sensaciones heredadas por sus antepasados, mucho menos a negar las fuerzas del azar, sino reinventarse con ellas creando nuevas formas de valorar. Lo que es lo mismo: crear nuevos instintos para interpretar un mismo mundo. El mundo se repite, es lo necesario, pero no se repite su modo de valoración, que es lo contingente, lo susceptible de cambiar; y en eso consiste la apuesta ética por excelencia de la filosofía nietzscheana. La ética nietzscheana reemplaza el sentido de la libertad de la voluntad como libre elección de motivos por el concepto de voluntad de poder afirmativa, aquella que interpreta de forma múltiple el devenir y puede disponer lúdicamente de los sentidos que le impone a los fenómenos. Además, es esa voluntad de poder la que permite que se manifiesten los distintos modos de valoración. Decimos que los modos de valorar tienen directa relación con los instintos porque en el pensamiento de Nietzsche son los instintos en relación, el cuerpo, el sí mismo el que interpreta y valora.

\section{Bibliografía}


- ARANA, J. Los filósofos y la libertad. Síntesis, Madrid, 2005,

- ASTRAdA, C. Nietzsche. Almagesto, Bs. As., 1992,

- BECERRA, Pablo Martínez. Nietzsche y el despliegue de la libertad. Universidad Adolfo Ibáñez, Valparaíso. En: Revista Philosophica, 31/I (2007

- CAlVO, E. La crítica de la Moral Kantiana desde Nietzsche. En: Revista Espiga, Año X, Julio-Diciembre de 2011

- COLL, R. Nietzsche: el pensador del sentido. En: "Immanuel Kant en el bicentenario de la publicación de la Crítica de la Razón Pura", Instituto Goethe de Córdoba, 1982

- DELEUZE, G. Nietzsche y la filosofía. Trad. Carmen Artal, Anagrama, Barcelona, 2008,

- -----------. Nietzsche. Trad. Isidro Herrera y Alejandro del Río, Arena, Madrid, 2006

- GEMES, K. Nietzsche on free will, authonomy and the souvereign individual En: Nietzsche on Freedom and Autonomy. Edited by Ken Gemes and Simon May, Oxford University Press, 2009

- KANT, I. Fundamentación de la metafísica de las costumbres. Trad. M. García Morente, Espasa Calpe, Madrid

- KANT. Crítica de la razón pura II. Trad. José Rovira Armengol. Losada, Bs. As., 1984

- MARCUSE, H. Eros y civilización. Trad. Juan García Ponce, Ariel, Bs. As., 1985

- MASSUH, V. Nietzsche y el fin de la religión. Editorial Sudamericana. 1985

- MINGOT MARCILLA María Jesús. El vértigo del Amor Fati: Libertad y Necesidad en Nietzsche. En: Revista de Filosofía. Vol. 35 núm. 1 (2010)

- MÜLLER-LAUTER, Wolfgang, "Der Organismus als innerer Kampf. Der Einfluss von Wilhelm Roux auf Friedrich Nietzsche", Nietzsche-Studien, VII, 1978

- NIEMEYER, C. Diccionario Nietzsche. Conceptos, obras, influencias y lugares. Edición española a cargo de Germán Cano, Biblioteca Nueva, Madrid, 2012

- NIETZSCHE, F. Así habló Zaratustra. Trad. Andrés Sánchez Pascual, Alianza, Madrid, 2004,

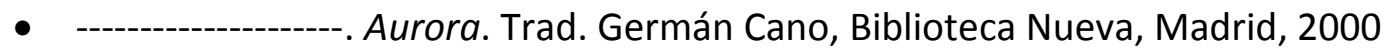

-

Bs. As., 2013

1999,

- - --------- La genealogía de la moral, Trad. Andrés Sánchez Pascual, Alianza, Bs. As., 2008

- ----------- Más allá del bien y del mal. Trad. Andrés Sánchez Pascual, Alianza, Bs. As., 1984, 
- -----------. Más allá del bien y del mal. Trad. Andrés Sánchez Pascual. Madrid, Alianza, 1984

2008

- --------- El crepúsculo de los ídolos. Trad. Daniel Gamper, biblioteca nueva, Madrid, 2002,

- POELLNER, P. Nietzschean Freedom. En: Nietzsche on Freedom and Autonomy. Edited by Ken Gemes and Simon May, Oxford University Press, 2009

- RICHARDSON, J. Nietzsche's Freedom. En: Nietzsche on Freedom and Autonomy. Edited by Ken Gemes and Simon May, Oxford University Press, 2009

- SÁNCHEZ, S. Lógica, verdad y creencia: algunas consideraciones sobre la relación Nietzsche-Spir. Universitas, Córdoba, 2001

- SANZ SANTACRUZ, V. De Descartes a Kant. Historia de la filosofía moderna. EUNSA, España, 2005,

- SLOTERDIJK, P. El pensador en escena. Trad. Germán Cano, Pre-textos, Valencia, 2000 